\title{
Interactive Tool in Digital Learning Ecosystem for Adaptive Online Learning Performance
}

\author{
Tippawan Meepung ${ }^{1}$, Sajeewan Pratsri ${ }^{2} \&$ Prachyanun Nilsook $^{3}$ \\ ${ }^{1}$ Faculty of Business Administration and Information Technology Rajamangala University of Technology \\ Tawan-Ok Chakrabongse Bhuvanarth, Thailand \\ 2 Faculty of Information Technology, Thepsatri Rajabhat University, Lopburi, Thailand \\ ${ }^{3}$ Division of Information and Communication Technology for Education, Faculty of Technical Education, King \\ Mongkut's University of Technology North Bangkok, Bangkok Thailand
}

Correspondence: Sajeewan Pratsri, Faculty of Information Technology, Thepsatri Rajabhat University, Lopburi, Thailand. E-mail: sajeewan.p@lawasri.tru.ac.th

$\begin{array}{lrr}\text { Received: June 17, } 2021 & \text { Accepted: July 8, } 2021 \quad \text { Online Published: July 12, } 2021 \\ \text { doi:10.5539/hes.v11n3p70 } & \text { URL: https://doi.org/10.5539/hes.v11n3p70 }\end{array}$

\begin{abstract}
The objective of this research was as follows: 1) to develop an interactive tool in a digital learning ecosystem for adaptive online learning performance; 2) to carry out a suitability assessment of this process. The documentary research method was used in this study. The results showed a model of an interactive tool in a digital learning ecosystem for adaptive online learning performance consisted of two phases. Phase 1: The development of an interactive tool in a digital learning ecosystem for adaptive online learning performance. This includes the following four design steps: 1) Reviewed literature and previous studies regarding an interactive tool, a digital learning ecosystem, and adaptive online learning performance to study the model, characteristics, and previous research. 2) Studied relevant research of an interactive tool in a digital learning ecosystem for adaptive online learning performance. 3) Designed an adaptive online learning performance model using an interactive tool in a digital learning ecosystem. 4) Developed a digital learning ecosystem. Phase 2: Evaluated the appropriateness of the interactive tool for an adaptive online learning performance model; this was checked for suitability by twelve experts and resulted in a conclusion. The results of the suitability evaluation revealed that the interactive tool for adaptive online learning performance was at the highest level.
\end{abstract}

Keywords: interactive tool, digital learning ecosystem, adaptive online learning performance

\section{Introduction}

Nowadays, learners routinely use computers to do homework; this is a change from a traditional environment to a digital environment. Resources are shared. Online learning distances learners from traditional learning methods in the classroom, but their academic performance is also associated with the effectiveness of online learning. (Zhu and Qi, 2018) Teaching and learning have increased rapidly in terms of the internet in that learning via online platforms is easy in that it uses computers and the internet in conjunction with technology and platforms in an online learning environment. Learning should be flexible. Adaptation and interaction in terms of the cognitive factors of the learner are monitored. Understanding lesson content is inspired by the interaction between learners, instructors and groups through communications technology. Strategies can be used to transform learning from being boring to being engaging and can energise learners by designing a new learning environment in conjunction with digital games in a variety of settings and with regard to a variety of subjects. Design in Learning focuses on developing and supporting learner dynamics. A joint search occurs involving participation in decision-making as the development of long-term memories lead to successful forms of learning. (Sebastian, 2021) In this study Quizizz gamified educational tools were used to gradually gain the interest of stakeholders. This results in learning by combining unique game elements such as leader-boards, memes and quiz reports, each of which can help increase engagement and positivity. Learning experiences occur in stress-free environments (Yunus and Hua, 2021) This makes students' interests and preferences stand out. The learning environment positively affects the performance of learners by facilitating the learning process and increasing learner satisfaction. It focuses on how to determine the characteristics of learners in terms of adapting to the learning environment target (Pratsri and Nilsook, 2020). Therefore, they meet the needs of the learner 
through interaction. Teaching and distance education technologies often indicate that interaction is an important variable in learning. (Lavoue et al., 2019) Online learning is different from classroom learning because both have different logic and learning methods. Online learning requires a particular teaching method with the content sequence based on a logic that differs from that which exists with regard to lectures or face-to-face teaching. One of the most important elements of these popular online learning systems is the review of behaviour.

\section{Research Objective}

\subsection{To Develop an Interactive Tool in a Digital Learning Ecosystem for Adaptive Online Learning Performance}

2.2 To Evaluate the Appropriateness of an Interactive Tool in a Digital Learning Ecosystem for Adaptive Online Learning Performance

\section{Literature Review}

\subsection{Interactive Tools}

\subsubsection{Polls and Quizzes}

Surveys are used as tools to manage online classes and can enhance the experience for learners and instructors. They can measure attitudes and motivation in real-time, which can be applied in a variety of ways, including quizzes, reviews, and smartphone-friendly applications (Kita, 2021). The use of co-teaching technology has a constructive influence on learners, encouraging a positive attitude towards ICT for learning and academic outcomes. Activities from instructors enable learners to participate in teaching activities using ICT tools that facilitate and optimize usage and interaction (Romero, García and Ceamanos, 2021).

\subsubsection{Games / Gamification}

Developing and supporting learning management based on social interaction frameworks The game promotes critical thinking and active participation of learners. It can lead to important learning patterns for a successful future. Interactive teaching is a way for learners to make learning more relevant and interesting through the game and play-focused teaching (Sebastian, 2021). In addition, learning with a game cultivates the necessary skills of critical thinking and creativity. Games and Education: Interaction between computer-generated objects and the real world helps with understanding and the development of long-term memory, an increases learner motivation and collaboration. Support learning improves learners' interest in learning, and helps instructors easily display information. It allows learners to visualize 3D structures, resulting in easy understanding (Hassan, Rahim and Shin, 2021).

\subsubsection{Interactive Infographics}

Learners are positively aware of interactive graphics data. Using visuals instead of information through computer use expands learners' perceptions. Leveraging human vision to better understand abstract information (Prandi et al., 2021). Using the potential of visual data transfer technology attracts greater attention from learners. This leads to the creation of a new teaching method that is more learner-centric. The information conveyed by these stimuli is recorded and organized in the short-term memory, and finally, it is stored in the long-term memory. Presenting content in different ways using interaction can create interest to affect performance and success. Infographics are one of the more interesting modes for presenting visual data through diagrams, videos, charts, text images, and more (Ismaeel and Mulhim, 2021). Instructors need to find a variety of ways to deliver content and encourage participation in the learning process. Learning occurs when stimuli attract the attention of the individual.

\subsubsection{Interactive Videos and Live Streaming}

Online learning continues at all levels of education. Education technology gives learners access to a vast amount of educational content. Although asynchronous content, such as YouTube videos, has access to independent education, you can use the asynchronous feature to create a video. The combination of video and asynchronous activities has led to a lonely learner experience (Hammad, Harpstead and Hammer, 2021). Interactive learning and interactive learning patterns are more appropriate than observation alone, and more interactive online learning experiences are required. Live streaming platforms create opportunities to support participatory learning. It is not the same as watching videos asynchronously. A live streaming platform supports text/chat interactions where learners can talk to other viewers (Hammad et al., 2021). Live streaming platforms are growing in popularity exponentially. This is an example of the need for a more engaging viewing experience, and it highlights the potential of live streaming as an educational medium. Using live streaming for learning is a growing subject of study in the research community. 


\subsubsection{Jam Board}

E-learning is growing rapidly, especially in higher education institutions. The advancement of new digital tools in education can be used through e-learning. Google Jamboard is a fun digital tool. The use of Google Jamboard in e-learning shows a positive and acceptable response to learners. Google Jamboard is ideal as a digital tool for enhancing teaching and learning methods (Penerimaan, Jamboard and Alat, 2021). Google Jamboard can be divided into two formats: a) Jamboard in the form of an interactive whiteboard. This is a useful digital tool that is suitable for learning in the $21^{\text {st }}$ century. It can change the way teaching and learning are done and promote communication skills; b) Critical thinking, creativity, and collaborative skills between students. This is an innovative tool that helps teachers interact with students. Reflecting their knowledge and gaps in learners' understanding, Jamboard is a great tool to help shape teaching at the moment and is a key component of both online and individual teaching (Jones, 2021).

\subsection{Online Learning}

Promoting student participation via online courses creates better overall engagement with the subject content. Increased interaction gives learners a sense of being a part of their studies. Helping learners not to feel isolated is a successful strategy that increases motivation and achieves greater relationships between students, both socially and cognitively (Sarah et al., 2021). To create an engaging learning experience for learners, technological advancements must be brought together to manage education. This is done by using effective media in both interaction and academic fields for effective, virtual synchronous learning. Related elements include Social Presence, Cognitive Presence, and Teaching Presence - these are available in both isolation and dependent scenarios. The first two elements focus primarily on the learner's experience, and the last part is on the instructor's responsibilities (Ligon \& Burns, 2021). The Online Learning Model consists of a set of elements designed to increase student engagement, retention, and overall satisfaction: 1. Learning Communities; 2. Interaction Between Students; 3. Teacher Presence; 4. Interaction with the Professions; 5. Flexible and Adaptive Learning; 6. Interactive Resources; 7. E-Assessment (University, 2021).

\subsection{Digital Learning Ecosystem}

The main goal of a learning ecosystem is to absorb change through the digital learning ecosystem. Examples of learning flows include networking and learning activities, where knowledge is created individually or collectively from the information. An example of a stream is the management information provided about educational management or learning measurement data. The learning ecosystem should have different types of interconnected elements that may act as medians or current changers. Infrastructure and digital learning tools and resources are mediated, as well as changing learning patterns, data, and streams. Components that change currents in the learning ecosystem include rules, change management, incentives, support, and training (Jeladze, Pata \& Quaicoe, 2017). A Digital Learning Ecosystem (DLE) consists of two input components and involves the development of an appropriate digital ecosystem for use in facilitating learners and instructors in terms of learning management, encouraging students to realize lifelong learning by giving them more freedom in terms of time control, location, and self-learning(Sarnok, Wannapiroon \& Nilsook, 2019). In this way, students will have the opportunity to participate in their studies, presenting ideas through digital storytelling to show students' potential, information skills, storytelling, data analysis, synthesis, communication skills, presentation skills, organizing ideas, questioning, and teamwork.

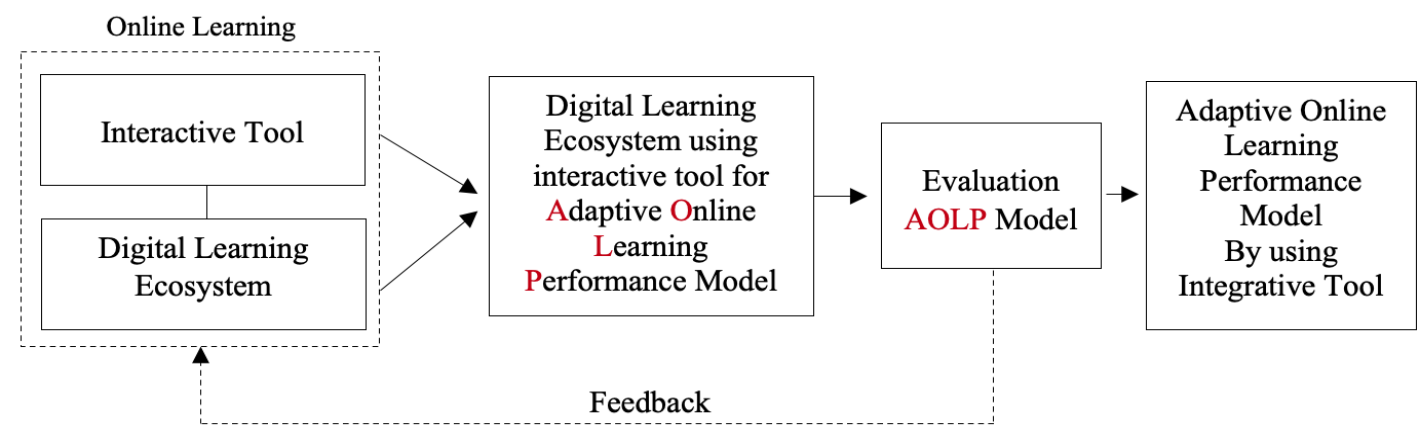

Figure 1. Conceptual framework

From Figure 1, the Adaptable Online Learning Performance Model (AOLP) consists of two input elements from 
online learning. These include developing an appropriate digital learning ecosystem using interactive tools from polls and quizzes, games/gamification, interactive infographics, interactive video, and live streaming jam boards to online learning. Examples of learning flows include networking and learning activities, where knowledge is created individually or collectively from information.

\section{Research Methodology}

The researcher reviewed previous studies in the field and developed the interactive tool in a digital learning ecosystem for adaptive online learning performance. This covered two phases as follows:

Phase I: The development of an interactive tool in a digital learning ecosystem model for adaptive online learning performance. This follows the design steps below:

1) Reviewed literature and previous studies regarding an interactive tool in a digital learning ecosystem and adaptive online learning performance. Studied the model, characteristics and earlier research.

2) Studied relevant research of an interactive tool in a digital learning ecosystem for adaptive online learning performance.

3) Designed an adaptive online learning performance model by using an interactive tool in a digital learning ecosystem with the following design steps: Part 1) Analysis or three parts analysis, which includes Instructor, Learner and a Digital Learning Ecosystem; Part 2) Activity or Digital Learning Ecosystem; and Part 3) Authentic Assessment Learning in a Digital Learning Ecosystem and applying the information obtained to improve the adaptive online learning performance.

4) Development of a Digital Learning Ecosystem, which can be divided into three parts: Part 1) Instructor; Part 2) Learner; Part 3) the Digital Learning Ecosystem using the interactive tool.

Phase 2: Evaluate the appropriateness of an interactive tool in a digital learning ecosystem for adaptive online learning performance via the following steps: 1) Creating evaluation tools to evaluate the validity of a digital learning ecosystem by an interactive tool which consists of four main components: 1) Interactive Process, 2) Interactive Tool, 3) Composition of Learning Management, and 4) Composition of Online Learning.

The model for a digital learning ecosystem, using an interactive tool for adaptive online learning performance, was checked for suitability by twelve experts.

\section{Results}

5.1 The Development of an Interactive Tool in a Digital Learning Ecosystem for Adaptive Online Learning Performance is as Follows

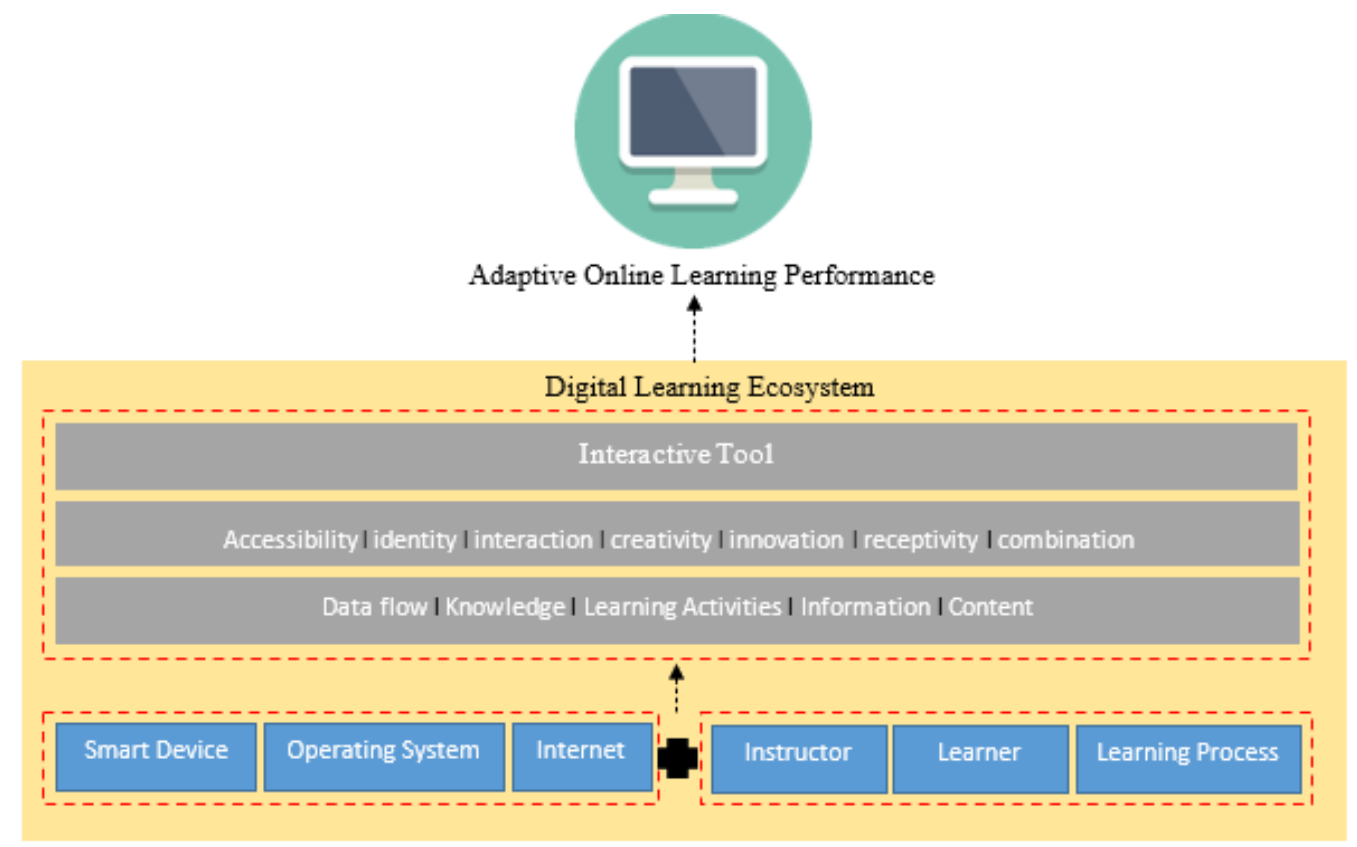

Figure 2. Interactive tool in digital learning ecosystem for adaptive online learning performance 
From Figure 2, the composition of a digital learning ecosystem and the learning process includes devices, operating systems and the internet. Learning management includes the instructors, teachers, and the learning process. In the learning ecosystem, content is delivered between learners and instructors, while information and knowledge activities are done together during online learning with the interactive tool to create interaction between learners. The interactive process consists of a combination of accessibility, identity, integration, creativity, innovation, and receptivity.

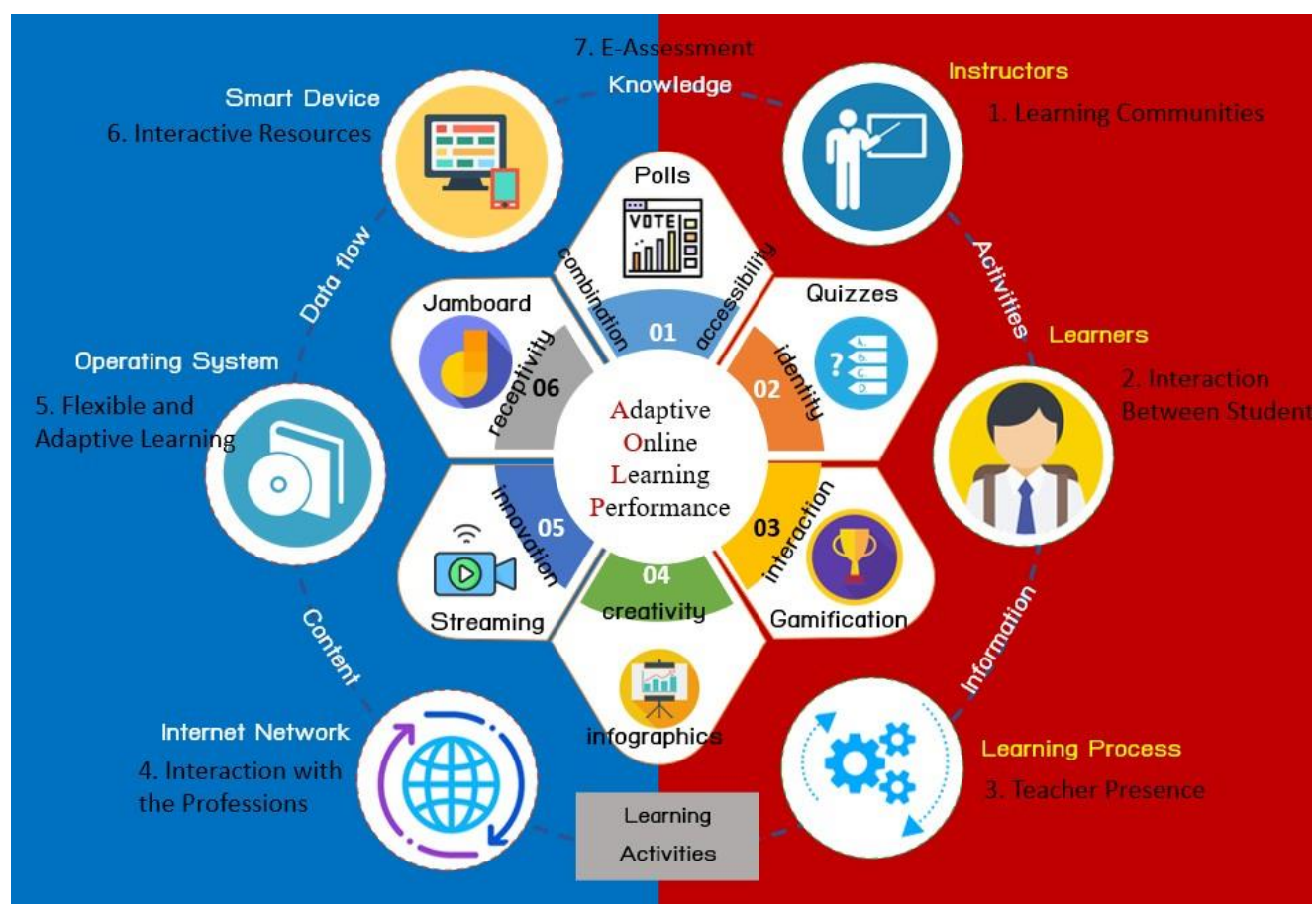

Figure 3. Interactive tool in digital learning ecosystem for adaptive online learning performance model

From Figure 3, shows the components of a digital learning ecosystem using an interactive tool for adaptive online learning. A Digital Learning Ecosystem consists of four components: Interactive Process: 1) accessibility, 2) identity, 3) interaction, 4) creativity, 5) innovation, 6) receptivity, and 7) combination; Interactive Tools: 1) polls, 2) quizzes, 3) gamification, 4) interactive infographics, 5) interactive videos and live streaming, and 6) Jam board; Composition of Learning Management: 1) instructors, 2) learner, and 3) learning process; Composition of Online Learning: 1) learning communities, 2) interaction between students, 3) teacher presence, 4) interaction with the professions, 5) flexible and adaptive learning, 6) interactive resources, and 7) e-assessment. 
5.2 The Evaluate the Appropriateness of Interactive Tool in Digital Learning Ecosystem for Adaptive Online Learning Performance are as Follows

Table 1. Table title (this is an example of table 1)

\begin{tabular}{llll}
\hline interactive tool in digital learning ecosystem for & \multicolumn{3}{l}{ Level of appropriateness } \\
\cline { 2 - 4 } adaptive online learning performance & $\mathrm{X}$ & S.D. & Description \\
\hline Digital Learning Ecosystem & & & \\
1. Interactive Process & & & \\
accessibility & 4.83 & 0.39 & Highest \\
identity & 4.75 & 0.62 & Highest \\
interaction & 4.83 & 0.39 & Highest \\
creativity & 4.58 & 0.67 & Highest \\
innovation & 4.67 & 0.49 & Highest \\
receptivity & 4.92 & 0.29 & Highest \\
combination & 4.67 & 0.49 & Highest \\
2. Interactive Tool & & & \\
Polls & 4.67 & 0.78 & Highest \\
Quizzes & 4.75 & 0.62 & Highest \\
Gamification & 4.67 & 0.65 & Highest \\
Interactive infographics & 4.83 & 0.39 & Highest \\
Interactive videos and live streaming & 4.83 & 0.58 & Highest \\
Jam board & 4.75 & 0.62 & Highest \\
3. Composition of Learning Management & & & \\
instructors & 5.00 & 0.00 & Highest \\
learner & 5.00 & 0.00 & Highest \\
Learning Process & 5.00 & 0.00 & Highest \\
4. Composition of Online Learning & & & \\
Learning Communities & 5.00 & 0.00 & Highest \\
Interaction Between Students & 4.75 & 0.45 & Highest \\
Teacher Presence & 5.00 & 0.00 & Highest \\
Interaction with the Professions & 4.83 & 0.39 & Highest \\
Flexible and Adaptive Learning & 4.92 & 0.29 & Highest \\
Interactive Resources & 4.92 & 0.29 & Highest \\
E-Assessment & 4.92 & 0.29 & Highest \\
\hline Total & 4.83 & 0.38 & Highest \\
\hline & & &
\end{tabular}

From Table 1, Evaluation results related to all 4 elements of digital learning ecosystem for adaptive online learning performance, it appears that there were 23 items the evaluation results received the highest level.

\section{Conclusion}

Today, the emphasis on online teaching is becoming increasingly important. Good learning outcomes have many relevant factors. These include technical aspects such as the quality of the equipment that transmits data and the stable quality of an internet signal. Also, the instructor must design the right learning materials for the learner in the form of online learning and apply educational technologies to stimulate the interests of learners, including those who are committed to success in online learning. The researchers saw the importance of tools for creating interactions between instructors and learners that help learners feel authentic during online learning. This reduces the gap between instructors and learners, helping them to adapt, so they do not feel alone during distance teaching and optimizes the success of online learning. This research discusses widely used interactive tools that are used in conjunction with educational management, such as voting via polls or asking for feedback from learners. Gamification is a process that helps learners achieve their desired goals. Rewards are offered for motivation. Instructors create teaching materials that capture learners' attention by applying interactive infographics, engaging them throughout the course, and using popular interactive videos and live streaming tools. These are used alongside joint commentaries or activities between instructors and learners with jam boards that use simultaneous collaboration. When designing steps to create interactions with learners in a learning ecosystem to enhance online learning, instructors should take into account their reach. Uniqueness indicates the identity of the learner who is currently using it. Interactive media should promote the creativity of open learners so that they 
can express their opinions in different ways.

\section{Discussion}

This is consistent with research by Yoko,2021 that uses interactive forms to create questions, effectively reviews study content, and collects information about the results of the quiz. The results show that the satisfaction of students using smartphones supports real-time and simple study management and increases student motivation (Kita, 2021). Gamification plays an important role, not only in accelerating learning but also by speeding up learners in terms of striving to accomplish tasks, but also increasing motivation to progress with proposals. Positive reinforcement means increasing user engagement and motivation by integrating game elements and strategies such as leader-boards, proms, badges or points, and feedback. The availability of these features promotes a sense of empowerment and increases participant engagement during a given work effort to achieve learning goals (Yunus \& Hua, 2021). Distance learning may cause students to lose interest. Instructors should apply gamification to increase students' interest in education(Nilsook \& Wannapiroon, 2014). The seven main techniques for engaging students include gamification, micro podcasts, online chat, consistent feedback, focus on students, professional needs, student calling, and storytelling. When students learn virtually, they lose the benefits of face-to-face contact which should promote their feelings as a result of interaction (Jain, 2021).

\section{Acknowledgments}

The authors would like to express our gratitude to Faculty of Business Administration and Information Technology Rajamangala University of Technology Tawan-Ok Chakrabongse Bhuvanart, Faculty of Information Technology, Thepsatri Rajabhat University, Lopburi, and King Mongkut's University of technology North Bangkok for their full support and promotion of this research.

\section{References}

Hammad, N., Erik, H., \& Jessica, H. (2021). Towards Examining the Effects of Live Streaming an Educational Game. Conference on Human Factors in Computing Systems - Proceedings. https://doi.org/10.1145/3411763.3451616

Hassan, S. A., Tariq, R., \& Soo, Y. S. (2021). ChildAR: An Augmented Reality-Based Interactive Game for Assisting Children in Their Education. Universal Access in the Information Society. https://doi.org/10.1007/s10209-020-00790-z

Ismaeel, D. A., \& Ensaf, N. A. M. (2021). The Influence of Interactive and Static Infographics on the Academic Achievement of Reflective and Impulsive Students. Australasian Journal of Educational Technology, 37(1), 147-62. https://doi.org/10.14742/ajet.6138

Jain, Y. (2021). Understanding the Effects of Virtual Education on Kindergarten Children and the Relationships between Teachers, Parents, and Children During a Global Pandemic Understanding the Effects of Virtual Education on Kindergarten Children and the Relationships.

Jeladze, E., Kai, P., \& James, S. Q. (2017). Factors Determining Digital Learning Ecosystem Smartness in Schools. Interaction Design and Architecture(S), 35, 32-55.

Jones, C. (2021). When Breakout Rooms Break, Jamboards Put the Pieces Together. Ticker: The Academic Business Librarianship Review, 5(2). https://doi.org/10.3998/ticker.16481003.0005.215

Kita, Y. (2021). Using Forms Quizzes to Enhance Students' Motivation in Language Learning at a Japanese University. 5(2), 219-35.

Lavoue, E, Baptiste, M., Michel, D., \& Sebastien, G. (2019). Adaptive Gamification for Learning Environments. IEEE Transactions on Learning Technologies, 12(1), 16-28. https://doi.org/10.1109/TLT.2018.2823710

Ligon, B., Burns, A., \& Thammasitboon, S. (2021). Creating a 'Community of Inquiry': A Framework for Optimizing the Virtual Education Experience. MedEdPublish, 1(10), 71. https://doi.org/10.15694/mep.2021.000071.1

Nilsook, P., \& Wannapiroon, P. (2014). International Distance Consulting via Web Conferencing. International Journal of Emerging Technologies in Learning, 9(4), 60-64. https://doi.org/10.3991/ijet.v9i4.3736

Penerimaan, T., Google, J., \& Sebagai, A. (2021). JuKu. p. 34-45.

Prandi, C., Chiara, C., Valentina, N., \& Paola, S. (2021). Designing Interactive Infographics to Stimulate Environmental Awareness: An Exploration with a University Community. Multimedia Tools and Applications, 80(9), 12951-68. https://doi.org/10.1007/s11042-020-09140-w 
Pratsri, S., \& Nilsook, P. (2020). Design on Big Data Platform-Based in Higher Education Institute. Higher Education Studies, 10(4), 36. https://doi.org/10.5539/hes.v10n4p36

Romero, E., García, L., \& Ceamanos, J. (2021). Moodle and Socrative Quizzes as Formative Aids on Theory Teaching in a Chemical Engineering Subject. Education for Chemical Engineers, 36, 54-64. https://doi.org/10.1016/j.ece.2021.03.001

Sarah, H., Yann, G., Peter, M., Caroline, L., Kerri, H., Karl, B., Katherine, E-W., \& Sid, P. (2021). Developing a Community of Inquiry in Distance Education Using Computer Conferencing. The Internet and Higher Education.

Sarnok, K., Wannapiroon, P., \& Nilsook, P. (2019). Digital Learning Ecosystem by Using Digital Storytelling for Teacher Profession Students. p. 21-26. https://doi.org/10.18178/ijiet.2019.9.1.1167

Sebastian, C. (2021). Games and Education: Designs in and for Learning. The Wabash Center Journal on Teaching, 2(1), 2021. https://doi.org/10.31046/wabashcenter.v2i1.2847

University, Charles Sturt. (2021). Online Learning Model.

Yunus, C., Callista, A., \& Tan, K. H. (2021). Exploring a Gamified Learning Tool in the ESL Classroom: The Case of Quizizz. Journal of Education and E-Learning Research, 8(1), 103-8. https://doi.org/10.20448/journal.509.2021.81.103.108

Zhu, M., \& Wang, Q. (2018). Empirical Research on Relationship between College Students' Social Identity and Online Learning Performance: A Case Study of Guangdong Province. Higher Education Studies, 8(2), 97. https://doi.org/10.5539/hes.v8n2p97

\section{Copyrights}

Copyright for this article is retained by the author(s), with first publication rights granted to the journal.

This is an open-access article distributed under the terms and conditions of the Creative Commons Attribution license (http://creativecommons.org/licenses/by/4.0/). 